Citation: T. Gettongsong, M. Taseidifar, R.M. Pashley (2020) New Resins for Ion Exchange Applications and a Process for Their Sustainable Regeneration. Substantia 4(2) Suppl.: 33-37. doi: 10.36253/Substantia-824

Copyright: (c) 2020 T. Gettongsong, M. Taseidifar, R.M. Pashley. This is an open access, peer-reviewed article published by Firenze University Press (http://www.fupress.com/substantia) and distributed under the terms of the Creative Commons Attribution License, which permits unrestricted use, distribution, and reproduction in any medium, provided the original author and source are credited.

Data Availability Statement: All relevant data are within the paper and its Supporting Information files.

Competing Interests: The Author(s) declare(s) no conflict of interest.

\section{New Resins for Ion Exchange Applications and a Process for Their Sustainable Regeneration}

\author{
Tanita Gettongsong, Mojtaba Taseidifar, Richard M. Pashley ${ }^{*}$ \\ School of Science, UNSW Canberra, Northcott Drive, Canberra, Australia \\ *Corresponding author: r.pashley@adfa.edu.au
}

\begin{abstract}
The report is concerned with the design and synthesis of a mixed bead resin for high salt level desalination. The resin allows for the simultaneous exchange of both anions and cations, within the same polymer. This improves the efficiency of desalination at seawater levels. A novel process for sustainable and low energy desalination for brackish water has already been achieved via ion exchange resins as explained below. The advance in resin technology improves a novel membrane process with closedcycle regeneration of the resin. It is a superior alternative to reverse osmosis.
\end{abstract}

Keywords: thermal decomposition, bubble column evaporator, zwitterionic polymer resin, desalination, ion-exchange resin, ammonium bicarbonate, hollow fibre membrane.

\section{INTRODUCTION}

Current desalination techniques like distillation and reverse osmosis (RO) are so energy intensive processes that they are often marginal economically. ${ }^{1}$ A promising alternative discussed in this volume comprises mixed cation and anion ion-exchange resins, that remove salt. It offers several advantages in desalination, such as low-input pressure, simple setup, high efficiency and also does not require an extensive pre-treatment. Success requires removal of the salt and regeneration of the resin by the ammonium bicarbonate technology described ${ }^{2-4}$ and further below.

Ion exchange beads, in typical commercial applications, are mixed and widely used in order to adsorb different ions onto their surfaces. The process has been used over many years in various water treatment processes, and consumes less energy than distillation and reverse osmosis. However, it has limited capacity to remove and adsorb ions in seawatwer and even fairly concentrated brackish water. An ion-exchange resin reaches a 'spent' point, at which the majority of the ion-receiver sites on the surface of the beads are depleted and no longer adsorb ions in aqueous solution. This problem can be resolved by maintaining separation of cationic and anionic beads following by regeneration of each with large volumes of strong acid and strong base. This limits the economic viability of the technique for desalination applications. ${ }^{2,5}$ 
Our published results ${ }^{2}$ have shown that ammonium bicarbonate $(\mathrm{AB})$ can regenerate the spent resin without the need for separation of cationic and anionic resins and also the use of strong acid and strong base regeneration. Ammonium bicarbonate $(\mathrm{AB})$ is a thermolytic salt, which is capable of decomposing in aqueous solution at low temperatures, ranging between 35 and $80{ }^{\circ} \mathrm{C}$. ${ }^{6}$ The decomposition is described by below reaction:

$$
\mathrm{NH}_{4} \mathrm{HCO}_{3(\mathrm{aq})} \triangleq \mathrm{NH}_{3(\mathrm{~g})}+\mathrm{CO}_{2(\mathrm{~g})}+\mathrm{H}_{2} \mathrm{O}
$$

Using an $\mathrm{AB}$ solution as regenerant resolves the regeneration issue, and apparently for the first time. Ammonium bicarbonate is unique in having the necessary properties for regeneration. The decomposition of the product $\mathrm{AB}$ solution also provides drinking water, as well as re-forming the resin. ${ }^{5}$

This work relates to use of mixed bead resin for high salt level desalination and also potential processes for regeneration of the resin. The resin material produced the polyampholytic hydrogel and zwitterionic resins to simultaneously exchange ions and cations in desalination at salt concentrations approaching seawater levels, and the regeneration process is comprised of washing the resin with high concentration of ammonium bicarbonate solutions. The recovery of the latter compound can be performed using either, a closed cycle hollow fibre membrane system or by using a suitable bubble column evaporator (BCE). These methods offer the advantage of re-using the ammonium bicarbonate as an in situ regenerator for the mixed bead resin desalination system.

\section{MATERIAL AND METHODS}

\subsection{Materials}

Certified reagent grade chemical (>99\% purity) ammonium bicarbonate $\left(\mathrm{NH}_{4} \mathrm{HCO}_{3}\right)$ was supplied by Sigma-Aldrich and was used without further purification. Aqueous solutions were prepared using deionized, ultrafiltered water (Milli-Q).

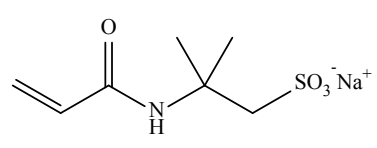

AMPS

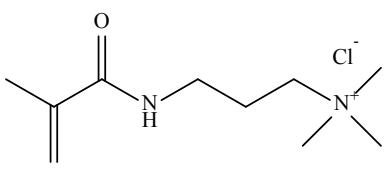

MPTC
Figure 1. Chemical structures of the cationic and anionic monomers used to produce the polyampholytic hydrogel.
For the decomposition experiment using a bubble column evaporator, a glass sinter column (Büchner type, Pyrex $^{\circledast}$ Borosilicate, VWR) with $120 \mathrm{~mm}$ diameter filled with $250 \mathrm{~mL}$ solution was used. The inlet air temperature was varied using a Tempco air heater (300W) with a thermocouple temperature monitor and an AC Variac electrical supply. The gases (air and nitrogen) were produced by cylinder (Coregas Pty Ltd, Australia) and a BOC gas flow meter.

\subsection{Synthesis of strong acid and strong base polymer resins}

The resin is synthesised by synthesis of two different strong acid and strong base resins. The resins comprise a chemical cross-linked polyampholytic resin and a crosslinked zwitterionic polymer, both resins containing strong acid and strong base on the same polymer.

2.2.1. A chemical cross-linked polyampholytic resin materials

\subsubsection{Materials}

2-acrylamido-2-methylpropanesulphonic acid sodium salt solution (AMPS) (anionic monomer), 3-(methacryloylamino) propyl-trimethylammonium chloride solution (MPTC) (cationic monomer), ethylene glycol dimethacrylate (EGDMA) (crosslinking agent), 25\% glutaraldehyde (GA) and alpha-glutaric acid (initiator) were used for synthesis. Several salts: $98 \%$ sodium chloride, 99\% sodium sulphate, magnesium chloride (AR grade) and magnesium sulphate (AR grade) were used to study swelling and conductivity and absorption properties. Chemical structures of AMPS and MPTC compounds are shown in Figure 1. All chemicals were purchased from Sigma-Aldrich, Australia as a reagent grade. 365 $\mathrm{nm}, 230$ Volts, 8 Watts UV-lamp and $365 \mathrm{~nm}$ Ultraviolet Crosslinker replacement tubes were purchased from John Morris Scientific Pty Ltd.

\subsubsection{Methods}

Several different reaction cells were tested for the UV polymerisation process to produce the polymer. The most suitable method was based on using an array of glass tubes of $1 \mathrm{~cm}$ diameter and $0.8 \mathrm{~cm}$ inner-diameter and of $10 \mathrm{~cm}$ length. Cross-linked polyampholytic resins were synthesised within the glass tubes using the one-step copolymerisation of an anionic monomer, a cationic monomer and a crosslink agent (EGDMA). 2-oxoglutaric acid was used as initiator. Cross-linked polyampholytic resins were produced with a range of 
different composition ratio. The ratio of momoners are shown in Table 1. 0.5 $\mathrm{M} \mathrm{NaCl}$ was used to fill the reaction cell. The UV reactions used 8 Watts at 250 volts, with a $365 \mathrm{~nm}$ ultraviolet lamp, for 15 hours. After reaction, the product was immersed in water for 1 week to allow the product to equilibrate and to wash out the residue unreacted chemicals.

\subsubsection{A crosslinked zwitterionic polymer}

\subsubsection{Materials}

p-Phenylene diamine and glutaraldehyde in dimethyl formamide (DMF) and 1,3-propane sultone in DMF were used as reactants for synthesis of the zwitterionic compounds. All chemicals were purchased from SigmaAldrich, Australia as a reagent grade.

\subsubsection{Methods}

This resin was prepared using $5 \mathrm{mmol}$ of $\mathrm{p}$-phenylene diamine in $20 \mathrm{~mL}$ of DMF and $5 \mathrm{mmol}$ of glutaraldehyde in $20 \mathrm{~mL}$ of DMF were prepared separately in a different beaker. The solution was mixed and refluxed at $80^{\circ} \mathrm{C}$ for $1 \mathrm{hr}$. Then, $15 \mathrm{mmol}$ of 1,3 -propane sultone in $10 \mathrm{~mL}$ of DMF was added in the reaction and refluxed at $70^{\circ} \mathrm{C}$ for $3 \mathrm{hr}$. The final product was washed several times with hot water to remove residual unreacted chemicals. Figure 3 shows the chemical structure of the zwitterionic polymer.

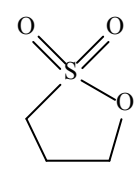

1,3-propane sultone

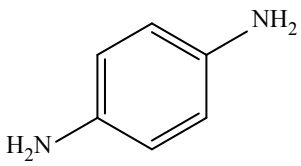

p-Phenylene diamine
Figure 2. Chemical structures of the cationic and anionic monomers used to produce the zwitterionic resins.

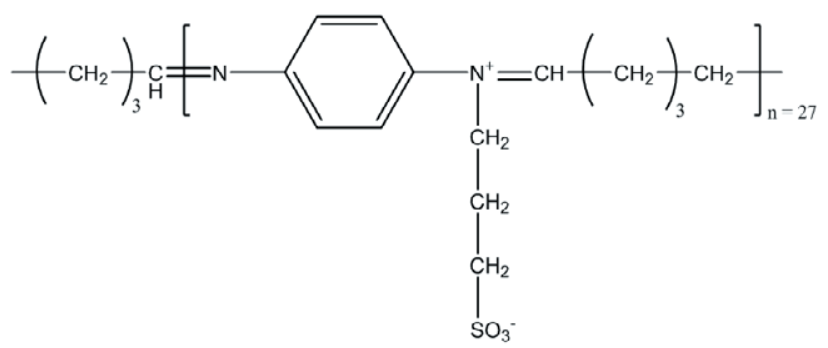

Figure 3. The zwitterionic polymer compound.
Table 1. The different molar ratios of reactant chemicals used for the polyampholytic resin syntheses.

\begin{tabular}{cccc}
\hline \multicolumn{2}{c}{ Monomers } & Crosslink agent & Initiator* \\
\hline AMPS & MPTC & & \\
\hline 1 & 1 & 0 & 1 \\
1 & 1 & 0 & 4 \\
1 & 1 & 1 & 1 \\
1 & 1 & 1 & 4 \\
1 & 1 & 2 & 1 \\
1 & 1 & 2 & 4 \\
\hline
\end{tabular}

${ }^{*}$ note that the initiator concentrations $1-4$ refers to the ratio of monomer and $0.25 \%$ mole of initiator (i.e. for ' 1 ', with ' 4 ' corresponding to $1 \%)$.

2.3. Bubble column evaporator system as an example for the ammonium bicarbonate recovery

Laboratory grade air and nitrogen separately was heated at $275{ }^{\circ} \mathrm{C}$ using a Tempco air heater $(300 \mathrm{~W})$ with a thermocouple temperature monitor and an AC Variac electrical supply to produce high-surface-area gas/water interface into a $120 \mathrm{~mm}$ diameter open-top glass column (Büchner type, Pyrex ${ }^{\circledast}$ Borosilicate, VWR) filled with 250 $\mathrm{mL}$ of the ammonium bicarbonate solution. The bubble column evaporator apparatus used to study improved decomposition with a high-temperature gas (air) flow is shown in our previous work. ${ }^{7}$ The actual temperature of the dry gas flowing into the solution was measured at the centre of the sinter by a Tenmars thermometer $\left( \pm 1.5^{\circ} \mathrm{C}\right)$ without any solution in the column. The gases (air and nitrogen) were produced from cylinders (Coregas Pty Ltd, Australia) and a BOC gas flow meter was used to measure flow rates. The temperature of the column solution was also continuously monitored using a thermocouple positioned at the centre of the column solution. The air flow at temperatures of $300-600{ }^{\circ} \mathrm{C}$ was needed to produce gas temperatures just above the glass sinter up to $275^{\circ} \mathrm{C}$, and this necessitated the use of steel and brass connectors for the downstream output from the heater and the use of FM Insulation Rock Wool as an insulating material.

Using the measured electrical conductivities of the $\mathrm{NH}_{4} \mathrm{HCO}_{3}$ solutions at different time intervals, the percent decomposition of $\mathrm{NH}_{4} \mathrm{HCO}_{3}$ at time $(t)$ in the either membrane or the bubble column evaporator process was calculated using the formula:

Decomposition $\%=\left[1-\frac{\left[\mathrm{NH}_{4} \mathrm{HCO}_{3}\right]_{t}}{\left[\mathrm{NH}_{4} \mathrm{HCO}_{3}\right]_{0}}\right] \times 100$

Where $\left[\mathrm{NH}_{4} \mathrm{HCO}_{3}\right]_{t}$ is the concentration of $\mathrm{NH}_{4} \mathrm{HCO}_{3}$ at time $(t)$ during the decomposition operation and 
$\left[\mathrm{NH}_{4} \mathrm{HCO}_{3}\right]_{0}$ is the initial concentration of $\mathrm{NH}_{4} \mathrm{HCO}_{3}$, just before pouring the solution into the membrane contactor or the bubble column evaporator. Electrical conductivity values of all the solutions were measured using a EUTECH CON 700 Conductivity Bench.

\section{RESULTS AND DISCUSSION}

\subsection{Polyampholytic and polyzwitterionic resins}

Ion adsorption equilibria were studied for both resins using monovalent $(\mathrm{NaCl})$ and divalent $\left(\mathrm{MgSO}_{4}\right)$ salt solutions. Typical results for the polyampholytic resin are shown in Figure 4 This graphs the absorption of salts by crosslink hydrogels. Similar adsorption isotherms were obtained with the polyzwitterionic resin, with a maximum $\mathrm{NaCl}$ adsorption of about $28 \mathrm{mmol} / \mathrm{g}$ (dry wt). Both resins indicate enhanced adsorption capacity compared with typical results obtained using commercial mixedbed strong acid-strong base systems. These give about 5 $\mathrm{mmol} \mathrm{NaCl} / \mathrm{g}$ (dry wt). The high adsorption rates show an increased efficiency of using the new resins in desalination compared to commercial resins. In addition, the latter resins are expected to have a shorter operating lifespan due to their regeneration using strong acid strong base This damages their polymeric structures.

The results in Figure 4 were obtained based on the electrical conductivities for different solutions when they were exposed to different ion exchange resins. These results are given below in Table 2-5.

\subsection{AB decomposition using the bubble column evaporator}

Some typical decomposition results (using air and nitrogen) obtained under different solution conditions

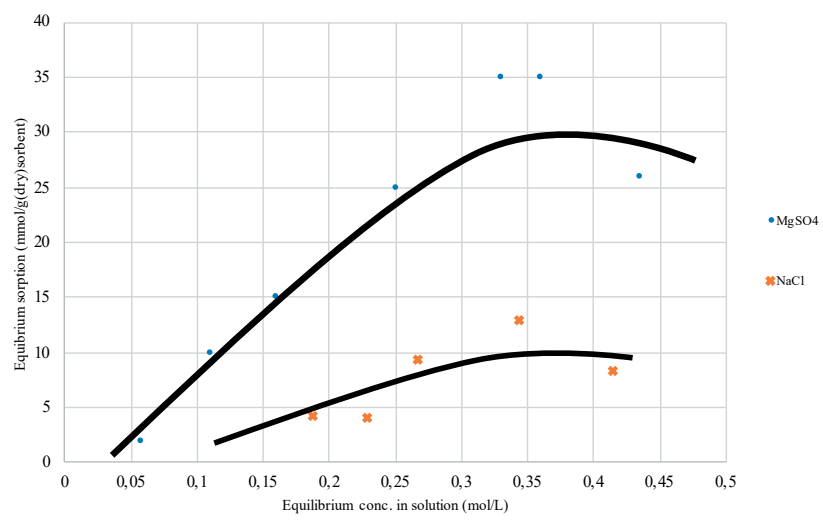

Figure 4. Adsorption of cross-linked polyampholytic resins equilibrated in $\mathrm{NaCl}$ and $\mathrm{MgSO}_{4}$.
Table 2. Electrical conductivity results for the hydrogel polymer dry sample (weight $0.05 \mathrm{~g}$ ) in $50 \mathrm{~mL} \mathrm{NaCl}$ solution.

\begin{tabular}{ccc}
\hline \multirow{2}{*}{ Concentration $(\mathrm{M})$} & \multicolumn{2}{c}{ Conductivity $(\mathrm{mS} / \mathrm{cm})$} \\
\cline { 2 - 3 } & Before & After \\
\hline 0.2 & 19.14 & 18.74 \\
0.25 & 23.2 & 22.8 \\
0.3 & 27.3 & 26.4 \\
0.4 & 34.9 & 33.7 \\
0.5 & 41.3 & 40.5 \\
\hline
\end{tabular}

Table 3. Electrical conductivity results for the zwitterionic polymer dry sample (weight $0.05 \mathrm{~g}$ ) in $50 \mathrm{~mL} \mathrm{NaCl}$ solution.

\begin{tabular}{ccc}
\hline & \multicolumn{2}{c}{ Conductivity $(\mathrm{mS} / \mathrm{cm})$} \\
\cline { 2 - 3 } Concentration $(\mathrm{M})$ & Before & After \\
\hline 0.1 & 10.43 & 10.34 \\
0.3 & 27.5 & 24.8 \\
0.5 & 35.4 & 34.1 \\
\hline
\end{tabular}

Table 4. Electrical conductivity results for $0.2 \mathrm{M}$ salts solution (Conductivity in solution).

\begin{tabular}{ccccc}
\hline & \multicolumn{4}{c}{ Conductivity $(\mathrm{mS} / \mathrm{cm})$} \\
\cline { 2 - 5 } & day 0 & day 1 & day 2 & day 3 \\
\hline $\mathrm{NaCl}$ & 18.98 & 18.66 & 18.62 & 18.38 \\
$\mathrm{MgSO}_{4}$ & 15.96 & 15.92 & 15.82 & 15.69 \\
DI water & 0.0025 & 0.01329 & 0.037 & 0.053 \\
\hline
\end{tabular}

Table 5. Electrical conductivity results for $0.2 \mathrm{M}$ salts solution (Conductivity in gel)

\begin{tabular}{|c|c|c|c|c|}
\hline & \multicolumn{4}{|c|}{ Conductivity $(\mathrm{mS} / \mathrm{cm})$} \\
\hline & day 0 & day 1 & day 2 & day 3 \\
\hline $\mathrm{NaCl}$ & & 15.64 & 16.73 & 16.3 \\
\hline $\mathrm{MgSO}_{4}$ & & 13.5 & 13.75 & 14.03 \\
\hline DI water & & 0.0363 & 0.042 & 0.0573 \\
\hline
\end{tabular}

are given in Figure 5. These results clearly demonstrate that the improved bubble column evaporator process is much more efficient for $\mathrm{NH}_{4} \mathrm{HCO}_{3}$ decomposition than the standard method using simple stirred heating (i.e. without bubble column evaporator) at the same solution temperature of around $57^{\circ} \mathrm{C}$. The results in Figure 5 obtained for different stirring conditions showed that 


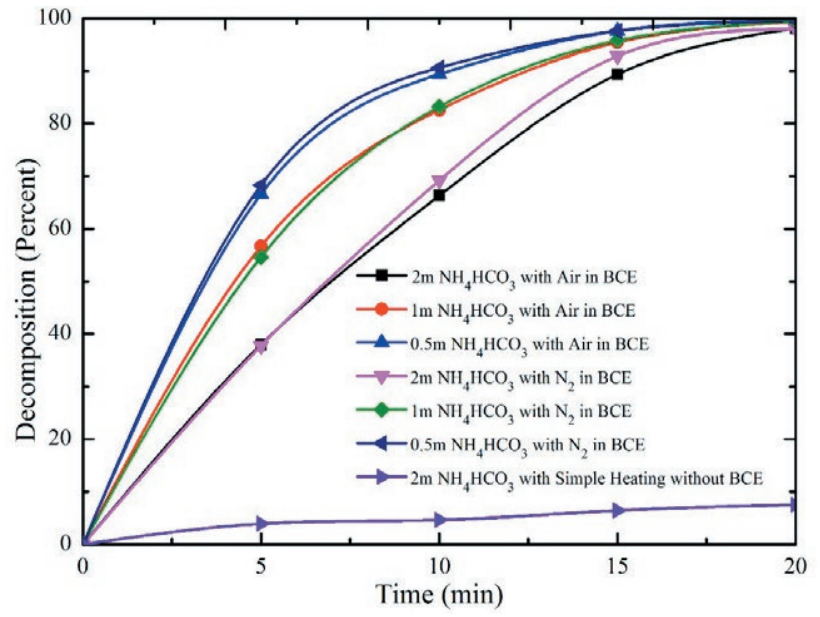

Figure 5. Percent decomposition of $\mathrm{NH}_{4} \mathrm{HCO}_{3}$ solutions at different concentrations in the bubble column evaporator (with an inlet gas (air and nitrogen) temperature of $275^{\circ} \mathrm{C}$ and column solution temperature of $57^{\circ} \mathrm{C}$ ) compared with simple heating in a stirred vessel at around $57^{\circ} \mathrm{C}$.

the decomposition rates for simple heating (without bubble column evaporator) remained the same, which indicates that the continuous mixing by the bubbling process in the bubble column evaporator did not itself contribute to the $\mathrm{NH}_{4} \mathrm{HCO}_{3}$ decomposition.

During the experiments, it was also observed that the presence of $\mathrm{NH}_{4} \mathrm{HCO}_{3}$ at concentrations above about $0.5 \mathrm{~m}$ inhibited bubble coalescence to a similar degree as $0.17 \mathrm{M} \mathrm{NaCl},{ }^{8}$ and that fine (1-3 $\mathrm{mm}$ diameter) bubbles were produced in the bubble column evaporator process. The thermal decomposition of ammonium bicarbonate solutions into ammonia and carbon dioxide gases and the resulting reduction in $\mathrm{NH}_{4} \mathrm{HCO}_{3}$ concentration can clearly be seen by the increase in bubble size.

\section{CONCLUSION AND FUTURE WORK}

An ion exchange resin was used for high salt level water desalination, with the resin comprising either a chemically cross-linked ampholytic polymer resin or a cross-linked zwitterionic polymer resin, on the same polymer chain, wherein the ampholytic polymer resin and the zwitterionic polymer resin each contain strong acid and base groups on the same polymer chain.

The current laboratory system could be scaled up and optimised either with a commercial mixed-bed resin (strong acid/strong base mixed resin) or a novel mixed bead resin of the type used in this study but using ammonium bicarbonate for the closed-cycle regeneration of the resin, which offers an energy efficient desalina- tion process. The resin regeneration process could also be combined with the bubble column evaporator method in order to recycle ammonium bicarbonate in a simple and efficient way. This can potentially be used as a new method to treat brackish groundwater in remote communities to replace current techniques, such as, reverse osmosis and thermal distillation which both have expensive maintenance requirements and are more difficult to establish.

\section{ACKNOWLEDGMENT}

The authors gratefully acknowledge the Australian Research Council for funding this research.

\section{REFERENCES}

1. I. C. Karagiannis, P. G. Soldatos, Water desalination cost literature: review and assessment, Desalination, 2008, 223, 448-456.

2. N. P. G. N. Chandrasekara, R. M. Pashley, Regeneration of strong acid/strong base mixed-bed resins using ammonium bicarbonate $(\mathrm{AB})$ for a sustainable desalination process, Desalination, 2017, 409, 1-6.

3. N. P. G. N. Chandrasekara, R. M. Pashley, Study of a new process for the efficient regeneration of ion exchange resins, Desalination, 2015, 357, 131-139.

4. N. Tarannum, M. Singh, Synthesis and characterization of zwitterionic organogels based on Schiff base chemistry, J. Appl. Polym. Sci., 2010, 118, 2821-2832.

5. N. P. G. N. Chandrasekara, R. M. Pashley, Enhanced ion exchange capacity of polyampholytic resins, Sep. Purif. Technol., 2016, 158, 16-23.

6. G. W. Gokel, Dean's handbook of organic chemistry, McGraw-Hill, New York, 2004.

7. M. Shahid, X. Xue, C. Fan, B. W. Ninham, R. M. Pashley, Study of a novel method for the thermolysis of solutes in aqueous solution using a low temperature bubble column evaporator, J. Phys. Chem. B, 2015, 119, 8072-8079.

8. V. S. J. Craig, B. W. Ninham, R. M. Pashley, The effect of electrolytes on bubble coalescence in water, J. Phys. Chem., 1993, 97, 10192-10197. 